\title{
Forensic investigation of cranial injuries due to blunt force trauma: current best practice
}

This article was published in the following Dove Press journal:

Research and Reports in Forensic Medical Science

6 October 2015

Number of times this article has been viewed

\author{
Elena F Kranioti ${ }^{1,2}$ \\ 'Department of Forensic Sciences, \\ Faculty of Medicine, University of \\ Crete, Heraklion, Crete, Greece; \\ ${ }^{2}$ Edinburgh Unit of Forensic \\ Anthropology, School of History, \\ Classics and Archaeology, University \\ of Edinburgh, Edinburgh, UK
}

\begin{abstract}
Blunt force trauma is one of the most common injuries encountered by the forensic pathologist in a variety of scenarios such as transportation fatalities, jumping or falling from heights, blast injuries, and being struck by firm objects. Blunt force injuries located in the cranium are often associated with the cause of death which makes their examination of vital importance in the medicolegal investigation of death. This article aims to review the existing knowledge on the mechanism of cranial blunt force injuries and the associated fracture patterns in order to facilitate the interpretation of such injuries in skeletonized or heavily decomposed bodies where soft tissue is no longer available. Current developments on theory and practice are also discussed. Despite the evidenced progress made in the past decades, trauma analysis in medicolegal settings remains a very challenging task, especially in the absence of soft tissue. It is thus imperative to work toward developing repeatable and scientifically acceptable methods with known error rates, in order to meet the increasing demands of the judicial system on the admissibility of evidence and expert witness testimony.
\end{abstract}

Keywords: cranial trauma, blunt force trauma, forensic anthropology, fracture, cranial injuries

\section{Introduction}

Forensic anthropology is a complementary discipline to forensic pathology for the examination of skeletal remains. Part of the duties of a forensic anthropologist is the examination and description of skeletal trauma and its possible association with the cause of death. Skeletal injuries can be divided into cranial and postcranial categories, according to their location. A different classification system is associated with the nature of the injuries (blunt force, sharp force, and ballistic trauma). Cranial vault injuries are categorized as depression, penetration, crushing, slashes, cuts, and slices. ${ }^{1}$ This work will focus on the analysis of cranial blunt force trauma (BFT), excluding ballistic trauma, based on existing and new knowledge and will discuss suggestions for best practice in forensic BFT analysis.

BFT trauma, as described in the draft guidelines on trauma analysis generated by the Scientific Working Group for Forensic Anthropology (SWGANTH) in 2011, "is produced by low velocity impact from a blunt object or the low velocity impact of a body with a blunt surface". ${ }^{2}$ Passalacqua and Fenton ${ }^{3}$ give a detailed description of the history of BFT, highlighting that it was around the 1980s when trauma analysis started to be considered as part of the forensic anthropologist's duties. It must be stressed that forensic examination of dead bodies is typically the duty of forensic pathologists/medical examiners, forensic anthropologists can, however, be involved 
in certain settings and in addition to assisting with biological profiling, trauma analysis has now become a regular task for them in various countries. Today, trauma analysis includes the assessment of ante-, peri-, or postmortem injuries, the identification of trauma patterns and possible association of trauma with certain objects, and generally the description and interpretation of traumatic events.

\section{Timing of injuries}

The first question that emerges in cases of skeletal damage is the timing of injuries and whether they coincide with the time of death. Forensic literature has been using the terms antemortem (prior to death), perimortem (at or around the time of death), and postmortem (after death) to describe the timing of injuries. ${ }^{4,5}$ However, the word "perimortem" has a different meaning in different disciplines. In medicolegal literature, "perimortem" means that the injury was provoked around the time of death and is probably associated with the cause of death, whereas forensic anthropologists and osteoarchaeologists consider "perimortem" injuries those that happen while the bone still has viscoelastic properties and before it enters the "dry" state. ${ }^{2,3,6-8}$ However, as noted by Berryman and Symes ${ }^{9}$ and other scholars, ${ }^{5}$ different parts of the same body reach the dry state at different postmortem intervals, which makes the definition even more problematic. In this paper, we will follow the anthropologist's definition of "perimortem" trauma.

Antemortem trauma is indicated when evidence of healing, such as signs of remodeling, osteophyte and/or callus formation or bony bridges, is present. These signs indicate that the bone was in the process of healing when death occurred. Although the process of healing begins immediately after sustaining an injury, it takes at least 1-3 weeks according to different sources ${ }^{5,8,10}$ until such signs became evident. Callus calcification (in which calcium comes from the fracture's margins) begins after the 3rd week. ${ }^{5}$ Barbian and Sledzik ${ }^{11}$ examined 127 crania of American Civil War victims for evidence of fracture healing in the form of osteoblastic and osteoclastic response and lines of demarcation, and found an osteoclastic response on the ectocranial surface approximately 5 days after injury. Osteoblastic and osteoclastic activity was reported in all cases 6 weeks after injury. Sauer ${ }^{4}$ cites Sledzik and Kelly's study on 257 crania from American Civil War victims where osseous remodeling was evident 7 days after injury. It must be stressed that while long bones tend to develop a callus formation as part of the healing processes, the skull normally heals with the development of bony bridges between the two fragments.
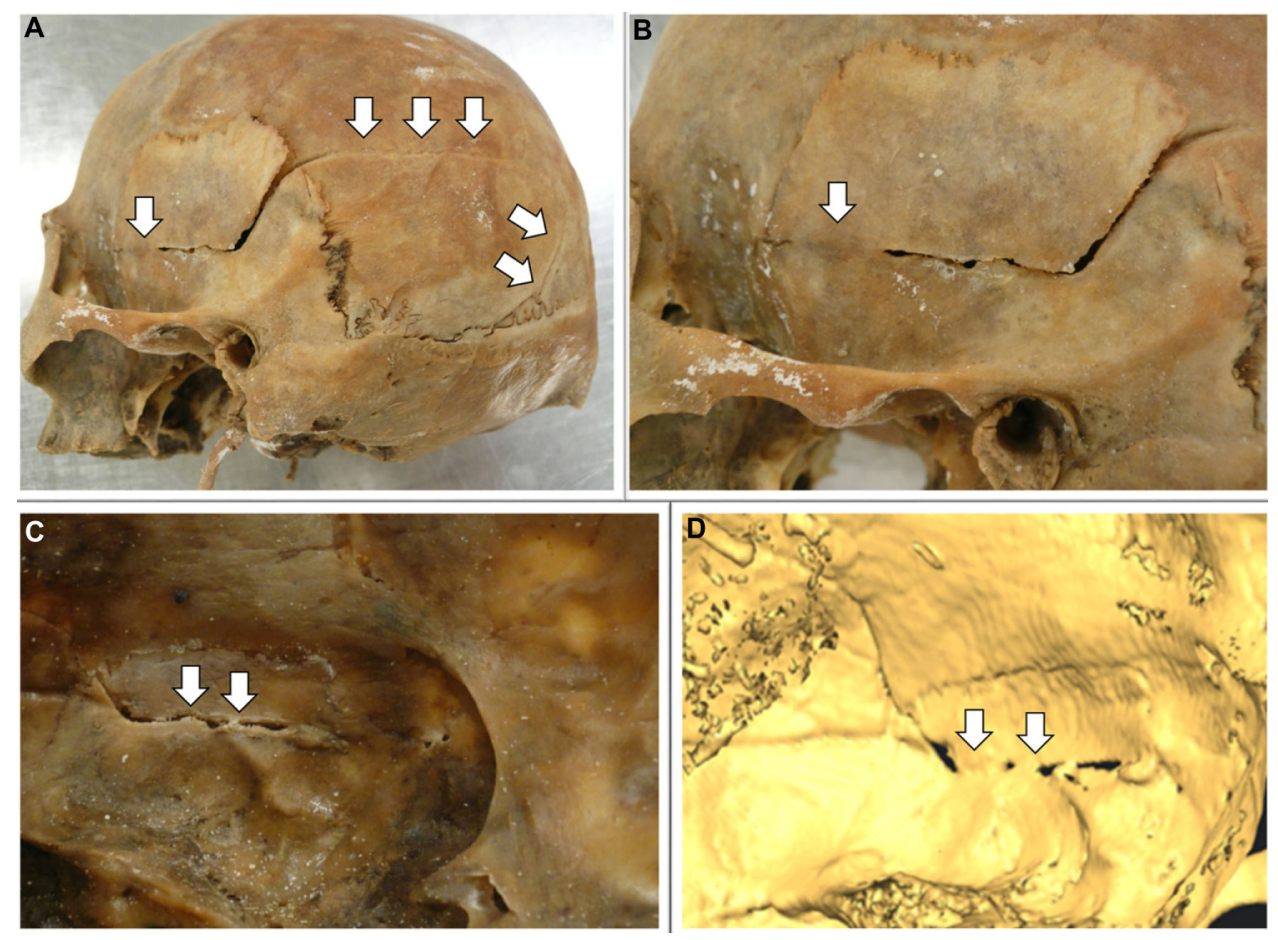

Figure I Fracture of the left parietal bone after car accident 25 years ago.

Notes: The bony bridges (arrows) on the ectocranial ( $\mathbf{A}$ and $\mathbf{B}$ ) and endocranial (C and $\mathbf{D})$ surfaces. (D) illustrates the endocranial surface in a 3D reconstruction from CT scan data. Source: Department of Forensic Sciences, University of Crete.

Abbreviation: CT, computed tomography. 
Figure 1 shows an example of healing of the endocranial surface of the left temporal bone after a BFT incident 25 years ago. The absence of such signs point to either perimortem injury or postmortem damage. Distinguishing the latter two types of damage heavily depends on the fracture pattern present.

Postmortem breakage is a result of taphonomic alterations and scavenging on skeletal remains. Postmortem fractures typically result in a fracture pattern with squared, sharp edges at right angles to the bone surface, and are likely to cause massive fragmentation of dry bone. Postmortem damage exhibits a rough or bumpy preponderant texture with blunt edges and irregular preponderant outline, as opposed to perimortem injuries which present a smooth preponderant texture and regular preponderant outline. ${ }^{12}$ Postmortem damage typically exhibits right-angled fracture margins, whereas peri-mortem injuries show obtuse or acute fracture angles. These characteristics have also been confirmed in computed tomography (CT) scan studies..$^{13}$ It should be noted that right angles have also been observed on fresh bone. ${ }^{14,15}$ In a recent study by the author on the examination of 88 fractures ( 52 perimortem from documented patient archives and 36 postmortem from documented archaeological materials) through CT scans, $88.68 \%$ of the perimortem fractures presented oblique or acute fracture angle and $73.68 \%$ of the postmortem fractures exhibited right discontinuity angles. Chi-square was calculated to be 36.8 which is statistically significant at the level of $P<0.001{ }^{16}$

Perimortem injury is indicated by plastic deformation localized to the area of injury, and by the presence of broken fragments still attached to the skull. ${ }^{1,17-19}$ Before bone has reached the dry state, it tends to splinter when fractured and small fragments remain connected to each other, ${ }^{8}$ often called "bone flakes" ${ }^{20}$ This indicates that the periosteum and other soft tissues were still present at the time of fracture, thus pointing to perimortem trauma. ${ }^{5}$ Additionally, when fresh bone bends, divisions are created between the diploe and the tables, which usually produce beveled fractures on the inner table (beveling) and a detachment of the outer table (delamination). ${ }^{20-22}$ Such injuries also exhibit the tendency of fracture lines to migrate toward structurally weaker areas of the skull, such as those where multiple blood vessels merge and the locations of naturally occurring holes, foramina. ${ }^{15,17}$ The absence of healing along fracture lines indicates that they may be associated with the individual's death. When an area of bone is pushed inwards, it does not entirely separate from the main corpus of the "wet" bone. This does not occur in dry bone, due to its lack of elasticity and the fact that dry bone fragments more readily than fresh bone., ${ }^{4,5,15}$ The nature of archaeological material and the ability of bone to retain some of its living characteristics for a short period after death, however, often obscures interpretation. . $^{5,8-10,15,21,22}$ Table 1 summarizes the proposed criteria for differentiating perimortem cranial trauma from postmortem damage from the current literature.

\section{Classification of cranial BFT}

Cranial BFT can be associated with homicides (eg, impact with a blunt object), suicides (eg, fall from height), and

Table I Criteria to differentiate perimortem trauma from postmortem damage

\begin{tabular}{|c|c|c|c|c|c|}
\hline Feature & Description & Antemortem & Perimortem & Postmortem & References \\
\hline $\begin{array}{l}\text { Signs of plastic } \\
\text { response }\end{array}$ & $\begin{array}{l}\text { Permanent deformation of } \\
\text { the bone after exceeding } \\
\text { the elastic response limit }\end{array}$ & $\begin{array}{l}\text { Presence or absence } \\
\text { depending on the fracture } \\
\text { location and nature }\end{array}$ & Present & Absent & $8,9,|7-2|$ \\
\hline Bone flakes & $\begin{array}{l}\text { Small bone fragments } \\
\text { attached to the impact site }\end{array}$ & NA & Present & Absent & $8,9,19$ \\
\hline Edge morphology & $\begin{array}{l}\text { The relative sharpness of } \\
\text { the fracture margin }\end{array}$ & Smooth & $\begin{array}{l}\text { Sharp, incomplete } \\
\text { or bend-edges }\end{array}$ & $\begin{array}{l}\text { Squared edges at right angles } \\
\text { to the bone surface-no bending }\end{array}$ & $12,15,16,19$ \\
\hline Fracture angle & $\begin{array}{l}\text { Angle between the } \\
\text { cortical table and the } \\
\text { direction of the fracture }\end{array}$ & NA & Acute or obtuse & Right & $12,15,16,19$ \\
\hline $\begin{array}{l}\text { Fracture texture or } \\
\text { tactile roughness }\end{array}$ & $\begin{array}{l}\text { Morphology of the broken } \\
\text { bone surface }\end{array}$ & Smooth & Smooth & Rough & $12,15,16,19$ \\
\hline Preponderant outline & & NA & Regular & Irregular & $12,15,16$ \\
\hline $\begin{array}{l}\text { Cortical delamination } \\
\text { or beveling }\end{array}$ & $\begin{array}{l}\text { Cleavage between the } \\
\text { diploe and the inner/outer } \\
\text { table }\end{array}$ & NA & Present & Absent & 9,19 \\
\hline $\begin{array}{l}\text { Cranial bone } \\
\text { remodeling }\end{array}$ & $\begin{array}{l}\text { Bony bridges between the } \\
\text { fragments }\end{array}$ & Present & Absent & Absent & 16 \\
\hline
\end{tabular}

Abbreviation: NA, not applicable. 
accidents (eg, impact of a driver or passenger in a motor vehicle accident).

Cranial BFT can be classified in several ways depending on the discipline, and terminology sometimes varies significantly. In this review, a simple classification system will be followed. Cranial injuries may be divided into linear, depressed and irregular or other (which covers all other types). Linear fractures include hairline or fissure fractures, which mainly appear on the vault, basilar fractures, which involve the cranial base, and diastatic fractures, which are basically the separation of pre-existing sutures. ${ }^{1,8,9,17-19}$ Hinge fractures are defined as crushing injuries, such as compression of the head between the ground and a heavy object (ie, a car tire). ${ }^{1,17,18}$ Transverse hinge fractures extend across the dorsum sellae of the skull, and can separate it into two. ${ }^{1,17,18}$

Depressed fractures are normally associated with slow loading in a small area of the skull, resulting in multiple fracture lines (comminuted) on the surface, while fragments are depressed or extend into the brain cavity. Stellate fractures are a result of an impact on the vault which results in imbedding of the bony fragment on the impact site and outbending of the periphery of the vault. This in turn results in a characteristic pattern of concentric fractures crossed by linear fractures. ${ }^{9,19}$ The exact mechanism of injury will be discussed later in this paper. Pond fractures are shallow depressed fractures which can be a result of compression or a continuation of a linear fracture. ${ }^{23,24}$

Ring fractures are circular fractures around the foramen magnum, produced as a result of a force driving the head against the spinal column. Such injuries are common in falls from height when the person lands on their feet or buttocks, ${ }^{1,17}$ and in collision accidents when the driver's top of the head impacts first, forcing the skull against the spine. ${ }^{17}$

Moritz ${ }^{17}$ and Spitz et al ${ }^{1}$ described cases of fractures that affect the inner table, while leaving the outer table intact (Plug fracture). The mechanism of this injury according to the first author is related to the "sturdy" vertical support of the diploe, whereas according to the second author it is "similar to the breaking of a plaster ceiling when the floor above is hit with the end of a broomstick". This can be interpreted as medium velocity impact on a localized small area which results in a loose fragment of bone endocranially that can be embedded in the brain. ${ }^{1}$

Rene Le Fort ${ }^{25}$ described the three classic patterns of facial fractures in his early experimental work. Le Fort's experiments $(\mathrm{N}=35)$ consisted of dropping cadaver skulls on flat surfaces, kicking them, or striking them with a wooden club or a metal shaft. He found three distinct fracture patterns, which he termed the "great weak lines" and they represent the Le Fort I, II and III fractures. ${ }^{26}$ Simply stated, after an impact on the face the palate may be separated from the maxilla (Le Fort I); the maxilla may be separated from the face (Le Fort II); or the maxilla and part of the mandibular condyles may be fragmented (Le Fort III). Le Fort also noted that although in some occasions facial and cranial fractures were both observed in his experiments, cranial fractures did not radiate out to the face..$^{25,26} \mathrm{~A}$ blowout fracture is a fracture of the orbital wall which usually occurs when a sudden blow to the eye pushes the intact globe back into the orbit. ${ }^{27}$ The sudden increase in intraorbital pressure in combination with the posterior displacement of the globe can result in a fracture of the floor of the medial wall of the orbit into the ethmoidal air sinuses. Other facial fractures include sagittal and dentoalveolar fractures as described by Di Maio. ${ }^{18}$

Moritz ${ }^{17}$ notes that the destructive result of an impact on the cranium may be quite distant from the impact site (remote fractures). More specifically, a fall on the back of the head or an impact on the top of the head may result in independent fractures of the orbital roofs due to the "contra-coup" movement of the orbital/frontal lobes against the thin areas of the skull. ${ }^{1}$ Such fractures are known in the forensic literature as contrecoup fractures. ${ }^{1,18}$ Similarly, fractures located at the site of impact are often called "coup fractures". ${ }^{1,18}$ Table 2 summarizes all types of cranial BFT as described by several authors.

\section{Etiology of BFT}

Head injuries have long been considered as the most common mechanical cause of death. ${ }^{17}$ It is the most common cause of death in road traffic accidents and falls or suicidal jumps from high places. ${ }^{28}$ Similar patterns of injury may be caused by different mechanisms, while the same mechanism may cause distinct patterns of injury. ${ }^{1,17,18}$ Blunt force cranial trauma can be a result of interpersonal violence (eg, assault), accident (eg, impact in traffic accidents), or self-inflicted injury (suicide via jumping from high places), whereas sharp force trauma is predominantly associated with interpersonal violence. Scholars agree that cranial injuries are more likely a result of interpersonal violence, as compared to postcranial fractures. ${ }^{17,18}$

Linear fractures are the most common type of cranial fracture, comprising $70 \%-80 \%$ of cranial injuries, ${ }^{29}$ and are thought to be associated with accidents such as falls, whereas depressed fractures exhibit a higher correlation to interpersonal violence. ${ }^{10,30}$ Clinical data indicate that the majority of 
Table 2 Terminology of blunt force injuries on the skull

\begin{tabular}{|c|c|c|c|}
\hline Type & Definition & Etiology & References \\
\hline Linear & $\begin{array}{l}\text { Fracture in a straight line that does not } \\
\text { cause bone displacement }\end{array}$ & $\begin{array}{l}\text { Low velocity caused by forces } \\
\text { with large mass }\end{array}$ & 23 \\
\hline Hairline/fissure & $\begin{array}{l}\text { Straight discontinuity of bone on } \\
\text { the cranial vault }\end{array}$ & & 23 \\
\hline Basilar & Linear fractures on the cranial base & & 1,18 \\
\hline Diastatic & Occur along the sutures & & $1,17,18$ \\
\hline Depressed & Inward displacement of bony fragments & $\begin{array}{l}\text { High velocity caused by forces } \\
\text { with low mass }\end{array}$ & $1,8,9,17,18$ \\
\hline Comminuted & $\begin{array}{l}\text { Multiple fracture lines (fragmentation) as a } \\
\text { result of crushing injuries }\end{array}$ & Low velocity/high impact & 17,23 \\
\hline Pond & Shallow depressed fractures & $\begin{array}{l}\text { Continuation of linear fractures or } \\
\text { compression }\end{array}$ & 23,26 \\
\hline Stellate & Star-shaped injuries & & $8,9,23$ \\
\hline Hinge fractures & Longitudinal or transverse crushing injuries & Compression & 1,18 \\
\hline  & $\begin{array}{l}\text { The outer table of the bone is intact while a } \\
\text { plug of the inner table is detached (broken out) }\end{array}$ & Low velocity impact-small surface & $1,10,17$ \\
\hline Ring fracture & Circular fracture around the foramen magnum & $\begin{array}{l}\text { Compression of lumbar spine after fall } \\
\text { with landing on feet/buttocks }\end{array}$ & $1,17,18$ \\
\hline Le Fort I & $\begin{array}{l}\text { Alveolar process of the maxilla on either side } \\
\text { of the face }\end{array}$ & Impact on the face & $\mathrm{I}, 18,24,25$ \\
\hline Le Fort II (“pyramidal” fracture) & $\begin{array}{l}\text { Maxilla may be separated from the face - } \\
\text { fracture extends into the orbits through the } \\
\text { interorbital region }\end{array}$ & Impact on the face & $\mathrm{I}, 18,24,25$ \\
\hline Le Fort III & $\begin{array}{l}\text { High transverse maxillar fracture through the } \\
\text { nasofrontal suture, through the medial orbital } \\
\text { wall and fronto-zygomatic suture, across the } \\
\text { arch and through the sphenoid }\end{array}$ & Impact on the face & $\mathrm{I}, 18,24,25$ \\
\hline Blowout fracture & $\begin{array}{l}\text { Fracture of the floor of medial wall of the orbit } \\
\text { into the ethmoidal air sinuses with an intact } \\
\text { orbital rim }\end{array}$ & $\begin{array}{l}\text { Sudden blow (eg, fist, ball, collision } \\
\text { accident) to the eye pushes the intact } \\
\text { globe back into the orbit }\end{array}$ & 27 \\
\hline Sagittal fractures & In sagittal plan through the maxilla & & $\mathrm{I}, 18$ \\
\hline Dentoalveolar fractures & $\begin{array}{l}\text { Separation of mandibular fragment that may } \\
\text { contain teeth }\end{array}$ & Direct force applied anteriorly or laterally & 1,18 \\
\hline Coup fractures & Fractures on the impact site & Direct force applied & $\mathrm{I}, 17,18$ \\
\hline Contrecoup or remote fractures & Fractures in an area away from the impact site & $\begin{array}{l}\text { Result of crushing injuries. Indirect force } \\
\text { transmitted through the moving brain }\end{array}$ & $1,17,18$ \\
\hline Open/compound fracture & $\begin{array}{l}\text { The skin is broken and the bone in contact } \\
\text { with external environment }\end{array}$ & & $\mathrm{I}, \mathrm{I} 7$ \\
\hline Closed/simple fracture & $\begin{array}{l}\text { The skin is not broken or cut - no exposure to } \\
\text { the external environment }\end{array}$ & & $\mathrm{I}, \mathrm{I} 7$ \\
\hline
\end{tabular}

cranial lesions inflicted with baseball bats result in cranial vault and base linear fractures. ${ }^{31}$ Moritz ${ }^{17}$ notes that if the head is free to move with the impact, the fractures tend to be linear or incompletely depressed, whereas if the head is immobilized (ie, against a solid surface) heavy blows will result in comminuted fractures with inward displacement.

For the differentiation between violent assault (eg, a blow to the head with a blunt object) and accidents (eg, fall), the hat brim line (HBL) rule is proposed in many forensic pathology handbooks as a single criterion. ${ }^{1,18}$ The HBL corresponds to the maximum circumference of the vault, and lesions above it are more frequent in blow rather than in fall injuries. Kremer et $\mathrm{al}^{32,33}$ have defined the HBL rule (see Figure 2), tested, and challenged its value. Instead, they suggest that it should be used in conjunction with other tested criteria, such as the side lateralization and the number of lacerations and the length of lacerations.

Their findings were based on a retrospective study of 113 forensic cases ( 29 cases of falls from one's own height, 21 cases of falls downstairs, and 63 cases of homicidal blows), excluding cases where a victim was struck while lying on the ground. They observed that linear fractures on the right side were more predominant in falls and have interpreted this observation based on the right-handedness predominance of the general population, highlighting that "their first protection when falling is to try to interpose their right 


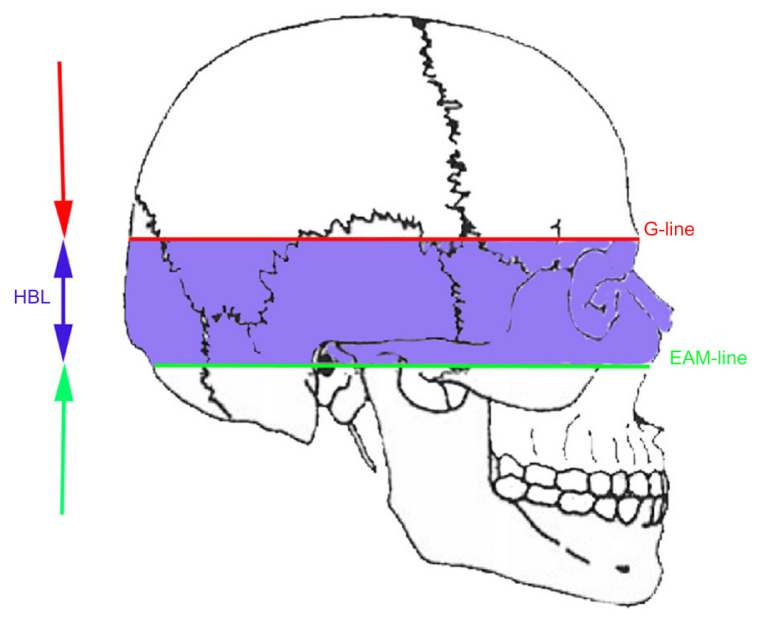

Figure $2 \mathrm{HBL}$ is the area located between two lines parallel to a line inspired by the Frankfort horizontal plane (horizontal plane passing through right and left porion points and the right and the left orbitale), the superior margin passing through the glabella (G-line), and the inferior margin passing through the center of the external auditory meatus (EAM-line).

Note: Adapted from Kremer et al. ${ }^{32}$ Discrimination of falls and blows in blunt head trauma: systematic study of the hat brim line rule in relation to skull fractures. Kremer C, Racette S, Dionne C-A, Sauvageau A. J Forensic Sci. 2008;53(3):716-719. Copyright (C) 2008 American Academy of Forensic Sciences.

Abbreviation: $\mathrm{HBL}$, hat brim line.

hand and therefore, the right side of the head is more prone to hit the ground". This work claims that left sided cranial fractures are more frequently associated with blows coming from a right-handed perpetrator. However, this pattern for blows is consistent with the perpetrator facing the victim. If the perpetrator is standing behind the victim, a blow with the right hand is more likely to hit to the right side of the head. The position of a depressed fracture on the posterior right side of the cranium is consistent with the pattern most frequently seen in violent assault trauma, assuming a righthanded aggressor. ${ }^{34}$

Guyomarc'h et a ${ }^{35}$ studied the same sample as Kremer et al, ${ }^{32}$ adding additional criteria such as scalp laceration length; calvaria fracture type; the number of facial abrasions, contusions, and lacerations (including mouth lesions); the presence of lacerations on the ear; the presence of facial fractures; the pattern of postcranial osseous and visceral trauma. The authors confirmed that HBL cannot be used as a single criterion for the differentiation of accidental falls from blows to the head and proposed a decision tree which included several additional criteria. They report a positive predictive value of $87 \%$ and a negative predictive value of $91 \%$ for the proposed method.

Fracasso et $\mathrm{al}^{36}$ challenge the findings of the three aforementioned studies ${ }^{32,33,35}$ with their letter at the Journal of Forensic Sciences in 2011. In this letter, they highlight that blunt force cranial injuries from falls do not lie above the HBL, if all the following conditions are fulfilled: a) standing position of the body before the fall, b) fall from one's height, c) flat floor, and d) the absence of intermediate obstacles. They also mention that according to Kratter (1921) "blows are possible at every region of the head with the exception of the base of the skull". ${ }^{36}$

The work of Ta'ala et a ${ }^{37}$ also contradicts the HBL rule. The authors studied 85 crania of the Khmer Rouge victims who were buried in mass graves outside of Phnom Penh, Cambodia, between 1975 and 1979. The initial assessment of ten skulls with BFT in the occipital region classified the fractures as ring or basilar fractures; however, a second evaluation gave different results. This research revealed that cranial trauma was more likely caused by execution with a variety of blunt weapons applied to the back of the head/ neck by Khmer Rouge soldiers, as described in historical sources and by eye witnesses. This also contradicts Kratter's rule mentioned earlier. ${ }^{36}$ Nevertheless, one cannot exclude additional actions taking place during the execution such as victims being kicked and/or hitting their head against the ground or other hard objects; thus, interpretation should be done with caution. It must be acknowledged that contextual information is always vital in trauma interpretation and general rules do not always apply.

Casali et a ${ }^{38}$ specifically studied the circumstances of suicidal falls in 307 cases from Milan, Italy. According to their findings, $40 \%$ of the victims exhibited cranial fractures and $30 \%$ exhibited facial fractures, with the latter being more common in falls from over $12 \mathrm{~m}$ high. Previous studies report variable frequencies of head trauma ranging from $25 \%$ to $91 \% .^{38}$ In most studies, however, falls to the ground are correlated with a higher incidence of cranial fractures, whereas suicidal falls in the water are associated with a higher incidence of abdominal injuries. ${ }^{39}$ Radiographic data ${ }^{40}$ show no statistically significant differences on the frequency of injuries in the skull between fallers and jumpers, whereas facial fractures are significantly higher in suicidal victims $(P<0.001)$. This is contrary to previous studies reporting no significant differences in the incidence of injuries. ${ }^{41}$

Lefevre et $\mathrm{al}^{42}$ investigated the differences in injuries caused by falls from less than $2.5 \mathrm{~m}$ high (accidental falls and falls due to sudden death) and homicides and reported no diagnostic value of the HBL in their study. The incidence of cranial fractures in homicides and accidental falls were similar ( $70 \%$ and $71 \%$, respectively), whereas the sudden death group showed substantially a lower incidence of cranial trauma (18\%). Depressed cranial fractures in homicides reached 37\%, whereas no depressed fracture was observed in either the accidental or sudden death group of falls. The authors suggested that the presence of at least one blunt 
laceration, one deep contusion and evidence intracranial trauma is highly indicative of homicide (area under the curve $=0.9391$ ). Despite the fact that intracranial trauma was found to be the most discriminatory factor for the differentiation of homicides versus falls, no statistically significant differences were found between the two groups based on the type of injury (subdural or extradural hematoma, cerebral contusion, subarachnoid hemorrhage, and diffuse axonal injury).

Multiple cranial injuries are more frequently associated with violent events than single cranial injuries. The estimation of the number of injuries and the time sequence in which they occurred followed a standard criterion known also as Puppe's rule: ${ }^{43}$ a fracture track from a second blow will not cross a previous fracture. ${ }^{1,8,9,17,18}$

\section{Biomechanics and BFT}

From a biomechanical point of view, cranial fractures are the result of different forces affecting the state of motion of the body (head) disrupting its least plastic tissue (bone). Bone is a weight-bearing anisotropic material that offers support to the rest of the body, allowing muscle stabilization through multiple insertions at different sites. It consists of collagen fibers, which provide elasticity, flexibility, and strength in tension, and inorganic components such as hydroxyapatite crystals, which provide rigidity, hardness, strength, and the capacity to brittle in compression. ${ }^{44,45}$ The minerals calcium and phosphate, together with collagen, constitute the organic element of the bone, which is responsible for approximately $60 \%-70 \%$ of the bone tissue. Water constitutes approximately $25 \%-30 \%$ of the bone tissue weight. ${ }^{46}$ The term anisotropic refers to the bone's property to react differently upon different loadings, depending on the site and the direction of the loading. Table 3 provides a summary table of basic bone biomechanics terminology based on several published manuscripts. ${ }^{1,8,9,17-21,44,46}$

Bone is a highly adaptive material: sensitive to disuse, immobilization or vigorous activity, and high loadings. Bone tissue adopts different properties according to the mechanical demands put on it. Wolff introduced Wolff's law according to which "Each change in the form and function of a bone or only its function is followed by certain definitive changes in its internal architecture, and secondary changes equally definitive in its external compliance, in accordance to the mathematics law". 46

The behavior of bone under different load conditions as with any other material - is defined by its strength and hardness. Essentially, this strength and hardness define bone's internal reaction to any external force applied on it. ${ }^{47}$ Because of its elastic properties, bone first absorbs energy upon loading up to a specific limit (the elastic limit). After this limit is reached, the external fibers of the bone tissue will start to exhibit micro-breaks and disconnection of the material within the bone (the deformation point). ${ }^{47,48}$ This process constitutes the plastic deformation phase on the load deformation curve (Figure 3).

The response of bone to load (strain) depends on the velocity (speed) and magnitude of the applied force. A slow load includes, but is not limited to, motor vehicle accidents, falls from heights, airplane crashes, and assaults. Upon slow loading bone can a) return to its original shape after the force

Table 3 Summary table of basic bone biomechanics terminology

\begin{tabular}{|c|c|}
\hline Term & Description \\
\hline Loading & The application of a force to an object \\
\hline Anisotropic & The bone behavior will change depending on the direction of the load application \\
\hline Viscoelastic & $\begin{array}{l}\text { The bone responds differently depending on the speed to which the load is applied and the } \\
\text { duration of the load }\end{array}$ \\
\hline Strength & Is defined by the point of failure or by the load sustained before the failure \\
\hline Hardness or elasticity module & $\begin{array}{l}\text { The ratio of stress to strain in the elastic region of deformation. Because bone is anisotropic, } \\
\text { the moduli in compression and tension differ in bone or the slope of the stress-strain curve }\end{array}$ \\
\hline Stress & Force per unit of area \\
\hline Strain & Relative deformation in response to loading \\
\hline Tension & Force directed away from the bone, which then becomes longer or is pulled apart \\
\hline Compression & $\begin{array}{l}\text { When force is applied toward the bone, it becomes shorter in the direction of the force; axial } \\
\text { loading }\end{array}$ \\
\hline Shear & Force is applied parallel to the surface, in opposite directions. Causes sideway sliding \\
\hline Elastic deformation & Bone can redeem its original shape after force is removed \\
\hline Plastic deformation & Bony is permanently deformed and cannot return to its original shape \\
\hline Load deformation curve & $\begin{array}{l}\text { Curve illustrating the relation between the load imposed (external force) and the quantity of } \\
\text { deformation (internal reaction) that takes place in the material }\end{array}$ \\
\hline Low-speed injuries & Blunt force trauma injuries \\
\hline High-speed injuries & Ballistic or blast injuries \\
\hline
\end{tabular}




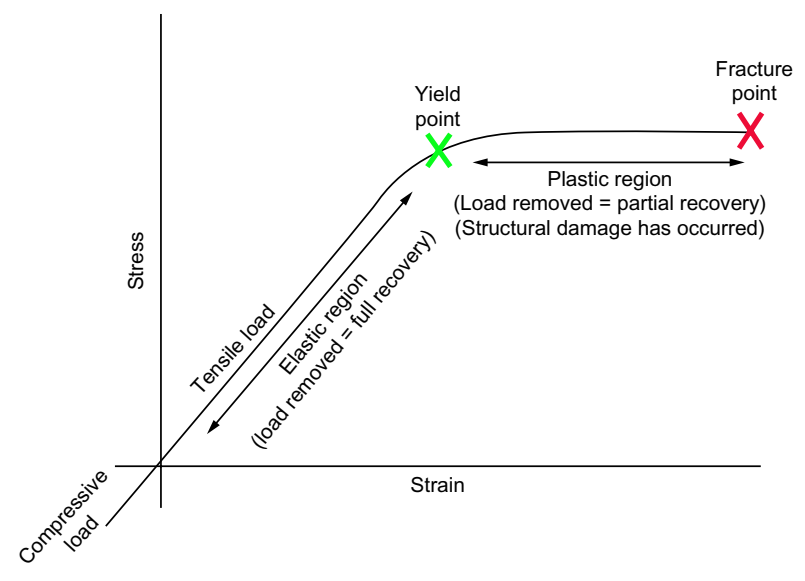

Figure 3 General load deformation curve.

Notes: Green $X$ represents the yield point and transition point from the elastic to the plastic phase, whereas the larger red $X$ corresponds to the point of failure (fracture). Adapted from Symes et al. ${ }^{21}$ Interpreting traumatic injury to bone in medicolegal investigations. In: Dirkmaat DC, editor. A Companion to Forensic Anthropology. Chichester: John Wiley \& Sons, Ltd; 2012:340-389. Symes SA, L’Abbé EN, Chapman EN, Wolff I, Dirkmaat DC. Copyright @ 2012 Blackwell Publishing Ltd.

is removed (elastic deformation), b) deform permanently (plastic deformation), or c) fracture. ${ }^{9}$ A rapid load is attributed to ballistic injuries, such as injuries due to the discharge of firearms, munitions, or explosives. Upon rapid loading, bone is more rigid and has greater tolerance before failure (fracture) ${ }^{49}$ The reason for this is that slow-loaded forces put bone under stress for a longer period of time, exhausting the bone physically, and subjecting it to both the elastic and plastic phase prior to failure. High-speed loading, on the other hand, causes the bone to resist up to a certain point and then shatters, with little or no plastic deformation..$^{9,20,21,50,51}$ It is worth noting that bone, due to its material properties, is a poor absorber of shock waves and rapid loads, and it may break more easily than the neighboring tissues. The final result after the application of a force on bone, however, is a combination of numerous intrinsic (eg, bone morphology, bone thickness, overlaying soft tissue thickness, cortical density, position of the body, etc) and extrinsic (eg, velocity and duration of impact, object shape, weight, etc) factors. ${ }^{8,9,17-21}$

In general, specific types of load will produce characteristic fracture patterns. According to Stewart, ${ }^{52}$ low-speed injuries involving a wide area typically produce linear fractures, whereas high-speed trauma results in smaller, depressed fractures. BFT (excluding ballistic trauma) is considered a low-speed injury. When a force is applied over a wide surface, it allows for the kinetic energy to be absorbed and thus results in smaller injuries, while a localized application of force is more destructive. The curved area of the skull, although it is stronger due to its shape, limits the surface area of contact and therefore typically results in severe injuries, though it always depends on the kinetic energy produced. The shape and size of the object used to apply the load is highly associated with the resulting fracture pattern.

When a head is either struck with or strikes an object having a broad flat surface area, the skull at the point of impact flattens out to conform to the shape of the surface against which it impacts. ${ }^{1,17,18}$ Figure 4A shows the result of a fall from height with the person landing on their head. Figure 4B illustrates a depressed fracture on the vault after an accidental fall from the first floor of a building (approximately $7 \mathrm{~m}$ height), with the person landing with the right side of the head between the ground and the front step door. Figure $4 \mathrm{C}$ is a result of an accidental fall on the ground after hitting an obstacle. Figure 4D is a result of a fall on the back of an individual from $1.70 \mathrm{~m}$ to $2 \mathrm{~m}$ height, landing on his back. The person was hanging on an iron door which eventually fell on top of the upper body and head.

Berryman and Symes ${ }^{9}$ describe a typical depressed fracture after a strike with a bat in four stages: a) low velocity impact on the skull causes fracture formation at the impact point due to the initial inbending of the cranial vault with peripheral outbending; inward displacement of the bony fragment due to plastic deformation; small fragments remaining in place, suggesting that the impact took place while soft tissue was present; b) radiating fractures in the area of outbending which starts at one or more points distant from the impact site, progress both toward the impact point and in the opposite direction (away from it); c) the radiating fractures stop when they meet the sutures; and d) formation of concentric fractures, perpendicular to the radiating fractures. It has also been documented that the cross-section morphology of radiating fractures is different from concentric fractures. ${ }^{9,53}$ This theory on the initiation of fractures in the periphery and then propagating toward the impact site, has been proposed by many forensic pathologists ${ }^{1,17}$ and has been supported by early experimental data, ${ }^{53}$ as well as with more recent work on animal models. ${ }^{54}$ Recent experimental work by Kroman et al, ${ }^{55}$ however, gave contradictory results. ${ }^{50,51}$ The authors used adult human cadaver heads and found fractures initiating at the site of impact (the center of the parietal) propagated away from this area. ${ }^{55}$ These results have not been so far reported by any other research group.

Figure 5 illustrates a cranial fracture after a kick from a horse which fits perfectly the description of a depressed fracture following a blow. ${ }^{9}$ The circular impression corresponds to the horseshoe.

Based on the direction of blows, the most inward displaced fragment is opposite to the direction of the striking object. 


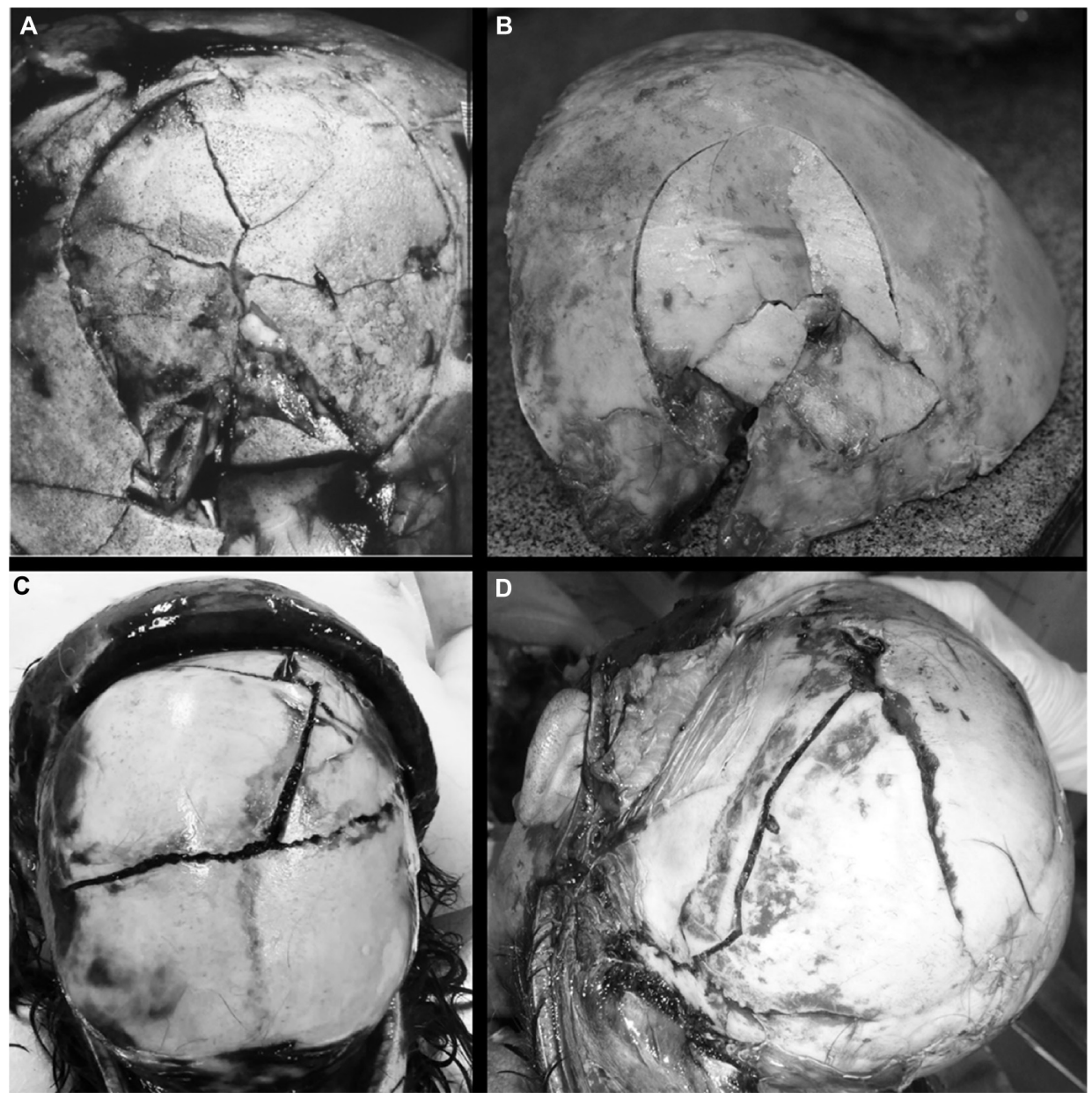

Figure 4 Examples of cranial blunt force trauma.

Notes: (A) Fall from height landing on the vault. Copyright (C) 200 I from Forensic Pathology. 2nd ed. by Di Maio VJM, Di Maio D. ${ }^{18}$ Reproduced by permission of Taylor and Francis Group, LLC, a division of Informa plc. (B) Fall from the first floor (approximately $7 \mathrm{~m}$ height) landing on the edge of a step. (C) Fall after striking an obstacle. (D) Fall and compression fracture between metallic object and ground. (B-D) Source: Department of Forensic Sciences, University of Crete.

Moritz ${ }^{17}$ notes that the lines of the fractures are typically longer on the side of the bone which is opposite to the surface of the impact. Additionally, a concentric fracture due to BFT is internally beveled, as opposed to a concentric fracture due to gunshot wound which tends to be externally beveled. ${ }^{20,53}$

Moritz ${ }^{17}$ differentiated cranial fracture patterns between a blow on free-moving head and on a head resting against a solid surface (eg, person laying on the ground). According to the author, blows to a free-moving head most likely result in linear or incomplete depressed fractures while heavy blows to the head resting against a solid surface (with resistance) are more likely to cause comminuted fractures with inward displaced bony fragments. This is consistent with several cases of falls with the vault landing on solid surfaces (Figure 4A and B). If the blow lands on an angle to the head, a linear fracture is more common depending on the surface of the strike. A series of experimental blows with various types of blunt objects, on artificial bone spheres (SYNBONE) $)^{56}$ (filled with porcine gelatin ${ }^{57}$ to simulate the human cranium) resulted in an interesting pattern. A single blow to a head (sphere) against a solid surface caused linear fracture independent of the angle (vertical or diagonal) and type of weapon (baseball bat, rolling pin, and window opener pole).$^{58}$ On the contrary, a vertical blow with a baseball bat on a free moving head resulted in a typical depressed fracture as seen in Figure 6. Naturally, these preliminary observations will need to be confirmed with a larger series of experiments.

Some authors ${ }^{10}$ suggest that a single linear fracture indicates less force than a more complicated fracture, whereas others ${ }^{18}$ suggest that the same amount of force is required for a linear and a compressed fracture with several fracture lines. Saukko and $\mathrm{Knight}^{24}$ reviewed the force required to cause fractures of the skull, and noted that the average adult head weighs $4.5 \mathrm{~kg}$. A simple fracture can occur by walking into a fixed object (force required $=73 \mathrm{~N}$ ), while a simple fall from $1 \mathrm{~m}$ with a frontal impact $(510 \mathrm{~N})$ can also result 


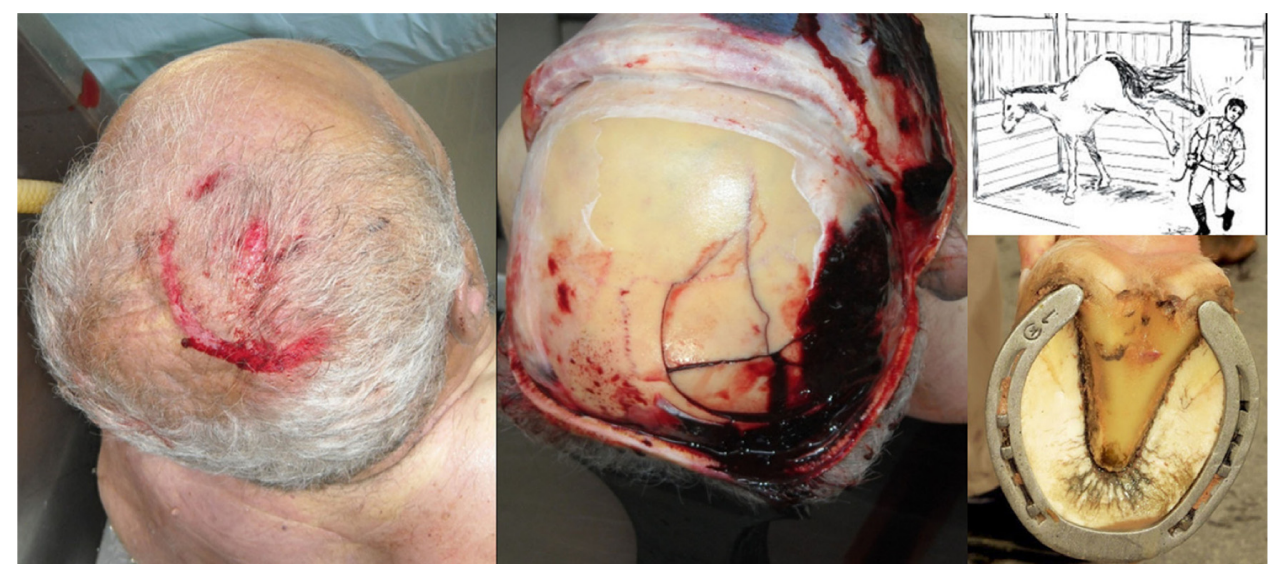

Figure 5 Cranial fracture after a kick from a horse.

Note: The circular impression corresponds to the horseshoe. Source: P Mylonakis, Forensic Pathologist, Medical Examiner's Office of Thessaloniki, Greece.

in linear or mosaic fractures. Fractures have also been absent when an impact force of $1,314 \mathrm{~N}$ was recorded. Preliminary findings of the same experiments on SYNBONE spheres reveal no fractures in cases where forces ranged from 381 to $608 \mathrm{~N}$, while forces over $622 \mathrm{~N}$ resulted in fractures of various shapes and extent. ${ }^{58}$ One should bear in mind that different skulls will have different tolerance to head injuries depending on the skull thickness, the age of the individual which affects the material properties of the bone, and all the extrinsic factors involving the impact. Experimental data are useful to have an understanding of the possibilities that an impact can have but they cannot provide a direct "diagnosis", as no simulation can be identical to the real event.

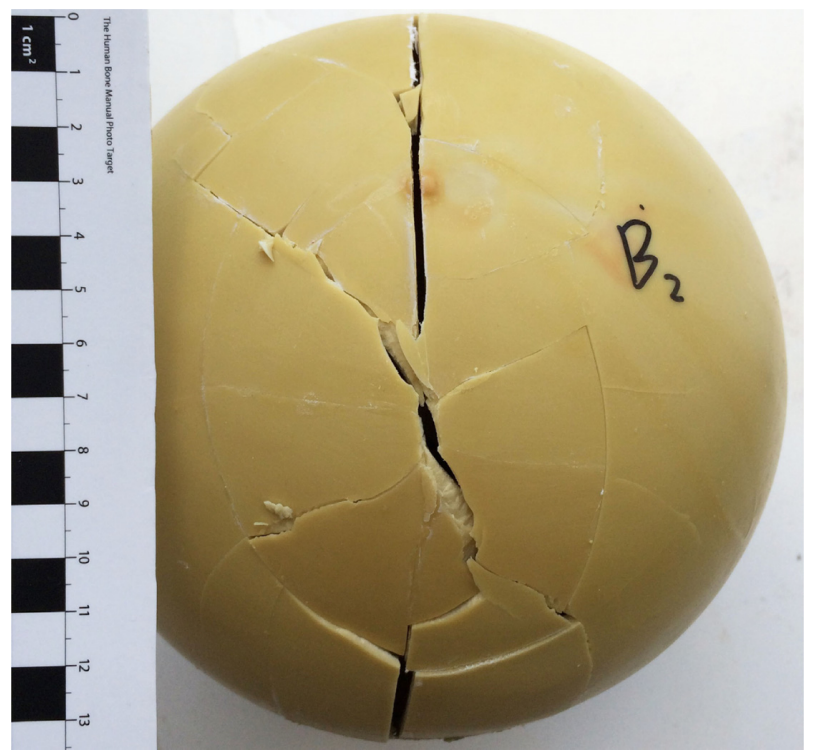

Figure 6 Depressed fracture on SYNBONE sphere filled with porcine gelatin simulating a free-moving head after strike with a baseball bat. Photograph courtesy of Yi-Hua Tang.

\section{Current best practice}

Skeletal injuries are often encountered during autopsy in various occasions (collision accidents, accidental or suicidal falls, and homicides). Spitz et $\mathrm{al}^{1}$ report that BFT is the most common type of injury found in autopsy and that the head is the most common location for BFT, especially in homicides. It is thus of vital importance to conduct a careful thorough analysis of the injuries on both the skin and soft tissue (if present), as well as on the hard tissue. A series of different techniques are available to the forensic pathologist when dealing with head trauma. These include radiographic examination of the body, macroscopic and microscopic examination of the skin and soft tissue including brain, as well as dissection and examination of the skull. If possible, medical imaging analysis with the use of CT scans would allow the virtual inspection of the endocranial surface of the skull without anatomical dissection. In the absence of soft tissue, however, the analysis becomes much more challenging. The analyst may need to remove the soft tissue remnants (sometimes dried tissue is not easy to manipulate) or macerate the skeletal fragments in order to properly observe the ectocranial surface, the edges of the fragments and the angle of the fracture lines. In the case of multiple cranial fragments, these need to be put together with the help of non-permanent glue or tape, then photographed and sketched, in order to capture the fracture lines from different views, and finally, a comprehensive description of the morphological characteristics of the injuries need to be recorded. ${ }^{21}$ Measurements of the fracture lengths and use of universal anatomical descriptions are recommended. ${ }^{2,21}$

Microscopic analysis can be useful in several ways as it allows the observation of bone fracture characteristics, hair, and remnants of other material such as metal or wood. 
Low magnification (Power $\times 3-40$ ) with a stereoscope is recommended by Symes et $\mathrm{al}^{21}$ especially for multiple blows (different impact sites, minimum number/sequence of blows) or tool impressions. When a tool impression is present, no attempt should be made to fit any possible weapon, as this could alter the characteristics on the bone. Instead, a comparison of positive casts of the suspected tool and tool mark has been proposed as best practice. ${ }^{2,21}$ Similarly, an expert should comment on whether a weapon/object would be consistent with a specific pattern, rather than to give a positive identification of the weapon.

The use of medical imaging technology is also increasing in the investigation of human remains with several new publications on virtual methods. ${ }^{59}$ In conclusion, trauma analysis is overwhelmed by a large number of new methodologies that seem to increase the possibilities for thorough analysis and interpretation.

Christensen and Crowder ${ }^{60}$ discussed the growing concern of the methods applied by forensic anthropologists and the doubt these methods are causing in the courtroom, specifically regarding the error rates. Trauma analysis is traditionally considered to be experience based and several authors in the past have argued that there is no room for quantifiable data. ${ }^{61}$ The emerging need for sound and reliable techniques in trauma analysis which comply with the Daubert criteria, ${ }^{62}$ however, has imposed a shift in the traditional methods of skeletal injuries which were mainly driven by the analyst's experience. Currently, new methods are relying on larger data sets and statistical analysis ${ }^{53}$ and books with known trauma cases are emerging more often. ${ }^{63}$ SWGANTH has produced a draft document of best practice for trauma analysis with regard to the admissibility criteria in the US courtroom. ${ }^{2}$ A compilation of these recommendations is also supported by recent reviews from the forensic scientific community. ${ }^{5,8,21}$

The new era for forensic anthropology dictates the development of reliable, repeatable, and scientifically acceptable methods with known error rates to comply with the admissibility criteria of the judicial system. Research on skeletal trauma analysis should focus on developing novel and accurate methodology that can satisfy these demands. As Passalacqua and Fenton ${ }^{3}$ correctly note, we need "a paradigm shift in how we approach skeletal trauma analysis" which would involve multidisciplinary approaches in hypothesis testing and systematic validation of the developed methodologies.

\section{Acknowledgments}

The author would like to thank Professor Manolis Michalodimitrakis and Dr Despoina Nathena, Forensic Pathologists,
Department of Forensic Sciences, University of Crete; Dr Panagiotis Mylonakis, Forensic Pathologist, Medical Examiner's Office of Thessaloniki for allowing access to the photographic material and forensic reports for the illustrations of cases of BFT; Professor Apostolos Karantanas and Mrs Aristea Haroniti, Radiology Department, University of Crete for allowing the access to anonymized CT scan data of patients suffering BFT; Yi-Hua Tang, Antoine Ruchonnet, Anna Evatt, Julieta G Garcia-Donas, and Caroline Lill for their contribution to the experiments on SYNBONE spheres; Meghan Dyer for providing the protocol on the experimental process and Mara Karell and Helen Langstaff for undertaking the linguistic review. Special thanks to the three anonymous reviewers and Professor Henrik Druid, Editor in Chief of the Research and Reports in Forensic Medical Science, for their valuable comments and suggestions in previous versions of this manuscript.

\section{Disclosure}

The author reports no conflicts of interest in this work.

\section{References}

1. Spitz WU, Spitz DJ, Clark R. Spitz and Fisher's Medicolegal Investigation of Death: Guidelines for the Application of Pathology to Crime Investigation. 4th ed. Springfield, IL: Charles Thomas Publisher, Ltd; 2006.

2. Scientific Working Group for Forensic Anthropology (SWGANTH). Trauma analysis; May 27, 2011. Available from: http://swganth.startlogic.com/Trauma.pdf. Accessed May 3, 2015.

3. Passalacqua NV, Fenton TW. Developments in skeletal trauma: blunt force trauma. In: Dirkmaat DC, editor. A Companion to Forensic Anthropology. Oxford: Blackwell; 2012:400-412.

4. Sauer N. The timing of injuries and manner of death: distinguishing among antemortem, perimortem, and post-mortem trauma. In: Reichs KJ, editor. Forensic Osteology: Advances in the Identification of Human Remains. 2nd ed. Springfield, IL: Charles C. Thomas; 1998:321-332.

5. Rodriguez-Martin C. Identification and differential diagnosis of traumatic lesions of the skeleton. In: Schmitt A, Cunha E, Pinheiro J, editors. Forensic Anthropology and Medicine: Complementary Sciences from Recovery to Cause of Death. NJ: Humana Press;2006:197-221.

6. Wieberg DAM, Wescott DJ. Estimating the timing of long bone fractures: correlation between the postmortem interval, bone moisture content, and blunt force trauma fracture characteristics. J Forensic Sci. 2008;53:1028-1034.

7. Nawrocki SP. Forensic taphonomy. In: S Blau, DH Ubelaker, editors. Handbook of Forensic Anthropology and Archaeology. World Archaeological Congress: Research Handbooks in Archaeology. Research Handbooks in Archaeology Series. Walnut Creek, CA: Left Coast Press; 2009:284-295.

8. Işcan MY, Steyn M, editors. The Human Skeleton in Forensic Medicine. 3rd ed. Springfield, IL: Charles C. Thomas; 2013.

9. Berryman HE, Symes SA. Recognizing gunshot and blunt cranial trauma through fracture interpretation. In: Reichs KJ, editor. Forensic Osteology: Advances in the Identification of Human Remains. Springfield, IL: Charles C. Thomas; 1998:333-352.

10. Lovell NC. Trauma analysis in paleopathology. Yearbook Phys Anthropol. 1997;40:139-170.

11. Barbian LT, Slezik PS. Healing following cranial trauma. J Forensic Sci. 2008;53(2):263-268. 
12. Dirkmaat DC, Cabo LL, Ousley SD, Symes SA. New perspectives in forensic anthropology. Yearbook Phys Anthropol. 2008;51:33-52.

13. Bonnichsen R. Pleistocene Bone Technology in the Beringian Refugium. National Museum of Man Mercury Series, Archaeological Survey of Canada Paper No 89. Ottawa, Canada; 1979.

14. Morlan RE. Toward the definition of criteria for the recognition of artificial bone alterations. Quat Res. 1984;22:160-171.

15. Fleming-Farrell D, Michailidis K, Karantanas A, Roberts N, Kranioti EF. Virtual assessment of perimortem and postmortem blunt force cranial trauma. Forensic Sci Int. 2013;229(1-3):162.e1-162.e6.

16. Kranioti EF. Can CT scan distinguish perimortem cranial trauma from postmortem damage? Invited talk: Third Annual Meeting of the International Society of Forensic Radiology and Imaging; May 15, 2014, Marseille, France.

17. Moritz AR. The Pathology of Trauma. 2nd ed. Philadelphia: Lea \& Febiger; 1954

18. Di Maio VJM, Di Maio D. Forensic Pathology. 2nd ed. Boca Raton, FL: CRC Press; 2001.

19. Jordana F, Colat-Parros J, Bénézech M. Diagnosis of skull fractures according to postmortem interval: an experimental approach in a porcine model. J Forensic Sci. 2013;58:S156-S163.

20. Berryman HE, Haun SJ. Applying forensic techniques to interpret cranial fracture pattern in an archaeological specimen. Int J Osteoarchaeol. 1996;6:2-9.

21. Symes SA, L'Abbé EN, Chapman EN, Wolff I, Dirkmaat DC. Interpreting traumatic injury to bone in medicolegal investigations. In: Dirkmaat DC editor. A Companion to Forensic Anthropology. Chichester: John Wiley \& Sons, Ltd; 2012:340-389.

22. Walker PL. A bioarchaeological perspective on the history of violence. Annu Rev Anthropol. 2001;30:573-596.

23. Galloway A. Broken Bones: Anthropological Analysis of Blunt Force Trauma. Springfield, IL: Charles C. Thomas; 1999.

24. Saukko P, Knight B, editors. Knight's Forensic Pathology. London: Arnold Publishers; 2004.

25. Le Fort R. Étude expérimentale sur les fractures de la machoire supérieure [Experimental study on fractures of the upper jaw]. Revue chir de Paris. 1901;23:208-227, 360-379, 479-507. French.

26. Dyer PV. Experimental study of fractures of the upper jaw: a critique of the original papers published by Rene Le Fort. Trauma. 1999;1:81-84.

27. Converse JM, Smith, B. Blowout fracture of the floor of the orbit. Tr Am Acad Ophth Otolaryn. 1960;64:676.

28. James SH, Nordby JJ, Bell S. Forensic Science: An Introduction to Scientific and Investigative Techniques. 2nd ed. Boca Raton, FL: CRC Press; 2005.

29. Rogers LF. Radiology of Skeletal Trauma. 2nd ed. New York: Churchill Livingstone; 1992.

30. Schulting RJ. Skeletal evidence for interpersonal violence: beyond mortuary monuments in southern Britain. In: Schulting R, Fibiger L, editors. Stick, Stones, and Broken Bones: Neolithic Violence in a European Perspective. Oxford: Oxford University Press; 2012:223-248.

31. Dujovny M, Onyekachi I, Perez-Arjona E. Baseball bats: a silent weapon. Neurol Res. 2009;31:1005-1011.

32. Kremer C, Racette S, Dionne C-A, Sauvageau A. Discrimination of falls and blows in blunt head trauma: systematic study of the hat brim line rule in relation to skull fractures. J Forensic Sci. 2008;53(3):716-719.

33. Kremer C, Sauvageau A. Discrimination of falls and blows in blunt head trauma: assessment of predictability through combined criteria. J Forensic Sci. 2009;54(4):923-926.

34. Aufderheide, AC, Rodriguez-Martin C. The Cambridge Encyclopaedia of Human Palaeopathology. UK: Cambridge University Press; 2003.

35. Guyomarc'h P, Campagna-Vaillancourt M, Kremer C, Sauvageau A. Discrimination of falls and blows in blunt head trauma: a multi-criteria approach. J Forensic Sci. 2010;55(2):423-427.

36. Fracasso T, Schmidt S, Schmeling A. Commentary on: Kremer C, Racette S, Dionne CA, Sauvageau A. Discrimination of falls and blows in blunt head trauma: systematic study of the hat brim rule in relation to skull fractures. J Forensic Sci. 2008;53(3):716-719. J Forensic Sci. Nov 2011;56(6):1662.
37. Ta'ala, SC, Berg, GE, Haden, K. Blunt force cranial trauma in the cambodian killing fields. Forensic Sci Int. 2006;51:996-1001.

38. Casali MB, Battistini A, Blandino A, Cattaneo C. The injury pattern in fatal suicidal falls from a height: an examination of 307 cases. Forensic Sci Int. 2014;244:57-62.

39. Li L, Smialek JE. The investigation of fatal falls and jumps from heights in Maryland (1987-1992). Am J Forensic Med Pathol. 1994;15: 295-299.

40. Teh J, Firth M, Sharma A, Wilson A, Reznek R, Chan O. Clin Radiol. 2003;58:482-486.

41. Richter D, Hahn MP, Ostermann PA. Vertical deceleration injuries: a comparative study of the injury patterns of 101 patients after accidental and intentional high falls. Injury 1996;27:655-659.

42. Lefevre T, Alvarez J, Lorin de la Grandmaison G. Discriminating factors in fatal blunt trauma from low level falls and homicide. Forensic Sci Med Pathol. 2015;11(2):152-161.

43. Madea B, Staak M. Determination of the sequence of gunshot wounds of the skull. J Forensic Sci Soc. 1988;28(5-6):321-328.

44. Frankel VH, Nordin M. Biomechanics of bone. In: Nordin M, Frankel VH, editors. Basic Biomechanics of the Musculoskeletal System. 3rd ed. Philadephia, PA: Lippincott Williams and Wilkins; 2001:26-59.

45. Shipman P, Walker A, Birchell J. The Human Skeleton. Cambridge, MA: Harvard University Press; 1986.

46. Alberts B, Bray D, Hopkin K, et al. Essential Cell Biology. London: Garland Science; 2009.

47. Holtrop ME. The ultra structure of bone. Ann Clin Lab Sci. 1975;5: 264-271

48. Hay ED, editor. Cell Biology of Extracellular Matrix. New York: Plenum Press; 1982.

49. Bankoff ADP, editor. Morfologia e Cinesiologia Aplicada ao Movimento Humano. Rio de Janeiro-Brasil: Guanabara Koogan; 2007.

50. Gurdjian ES, Webster JE, Lissner HR. The mechanism of skull fracture. Radiology. 1950;54:313-339.

51. Gurdjian ES. Impact Head Injury. Springfield, IL: Charles C. Thomas; 1975.

52. Stewart TD. Essentials of Forensic Anthropology. Springfield, IL: Charles C. Thomas; 1979.

53. Hart G. Fracture pattern interpretation in the skull: differentiating blunt force from ballistics trauma using concentric fractures. J Forensic Sci. 2005;50(6):1276-1281.

54. Baumer T, Passalacqua NV, Powell B, et al. Age-dependent fracture characteristics of rigid and compliant surface impacts on the infant skull - a porcine model. J Forensic Sci. 2010;55(4):993-997.

55. Kroman A, Kress T, Porta D. Fracture propagation in the human cranium: a re-testing of popular theories. Clin Anat. 2011;24(3):309-318.

56. SYNBONE Hollow Spheres. SYNBONE anatomical models for education: ballistics testing products [online]; 2013. Available from: https:// www.synbone.ch/wEnglish/catalogue/index.php?navanchor=1010042. Accessed July 24, 2013.

57. Sigma-Aldrich Company. Gelatin from porcine skin for ballistic analysis Type 3 (online); 2014. Available from: http://www.sigmaaldrich.com/ catalog/product/fluka/42043?lang=en\&region=GB. Accessed May 25, 2015 .

58. Ruchonnet A, Diehl M, Kranioti EF. Cranial BFT trauma on free-moving vs resting on solid surface head, in preparation.

59. Dedouit F, Savall F, Mokrane FZ, et al. Virtual anthropology and forensic identification using multidetector CT. Br J Radiol. 2014;87(1036): 20130468.

60. Christensen AM, Crowder CM. Evidentiary standards for forensic anthropology. J Forensic Sci. 2009;54:1211-1216.

61. Grivas CR, Komar DA. Kumho, Daubert, and the nature of scientific inquiry: implications for forensic anthropology. J Forensic Sci. 2008;53: 771-776.

62. Daubert v. Merrell Dow Pharmaceuticals, Inc. 509 US 579; 1993.

63. Kimmerle EH, Baraybar JP. Skeletal trauma: identification of injuries resulting from human rights abuse and armed conflict. Boca Raton, FL: CRC Press; 2008 


\section{Publish your work in this journal}

Research and Reports in Forensic Medical Science is an international, peer-reviewed, open access journal publishing original research, reports, reviews and commentaries on all areas of forensic medical science. The manuscript management system is completely online and includes a very quick and fair peer-review system. Visit http://www.dovepress.com/ testimonials.php to read real quotes from published authors.

Submit your manuscript here: http://www.dovepress.com/research-and-reports-in-forensic-medical-science-journal 